\title{
Paterno-Büchi reaction on 5-methyl-2-furylmethanol derivatives
}

\author{
Maurizio D’Auria and Rocco Racioppi \\ Dipartimento di Chimica, Università della Basilicata, Via N. Sauro 85, 85100 Potenza, Italy \\ E-mail: dauria@unibas.it
}

(received 03 Jan 00; accepted 25 Apr 00; published on the web 03 May 00)

\begin{abstract}
A photochemical reaction of 5-methyl-2-furyl-phenylmethanol (4) with benzophenone gave two $2+2$ adducts 5 and 6 in 1:1 ratio. The reactions of 4 with 4,4'-dimethoxybenzophenone, benzaldehyde or 4-methoxybenzaldehyde formed adducts 7, 10 or 11 respectively on the side of furan bearing the methyl group while with 4,4'-dichlorobenzophenone gave 8 on the other side of the molecule. Regiochemistry of the reaction can be explained assuming a single electron transfer process followed by radical coupling of the reagents. The different stability of intermediates explains the observed regioselectivity.
\end{abstract}

Keywords: Paterno-Büchi reaction, benzophenone, cycloadditions

\section{Introduction}

The photochemical reaction of furan with carbonyl compounds to give the corresponding oxetanes (Scheme 1) has been extensively studied in organic chemistry ${ }^{1-5}$ and several synthetic applications of this method have been reported. ${ }^{6-12}$
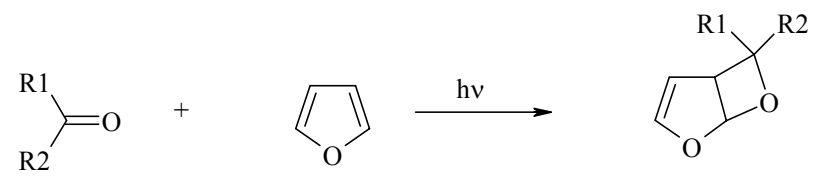

\section{Scheme 1}

Some years ago Carless found that 2-acetylfurans showed remarkable selectivity in cycloaddition reactions with aromatic aldehydes. ${ }^{13}$ Recently we reported that the reaction between aromatic aldehydes and ketones with 2-furylmethanols give the corresponding adducts in good yields with high regio-, stereo-, and enantioselectivity. ${ }^{14}$ We observed that the reaction occurred on the most hindered side of the molecule. This behavior was explained assuming the presence of an electron transfer process (in which the hydroxyl group plays an important role) followed by radical coupling between furyl carbon in $\alpha$ position and the oxygen on the carbonyl group.

Now we report our results obtained using 5-methyl-2-furylmethanols as substrates to verify 
whether the observed regioselectivity depends on a previous interaction between the reagents or on steric factors.

\section{Results and Discussion}

In our previous work we found that the irradiation of 2-furyl-benzylic alcohol (1) in the presence of benzophenone gave a 10:1 mixture of regioisomeric products 2 and $3(\mathrm{R}=\mathrm{Ph})$ (Scheme 2) with 2 as the main product. On the contrary, a similar reaction was carried out in the presence of benzaldehyde, we obtained a 6:4 mixture of products where the regioisomer $3(\mathrm{R}=\mathrm{H})$ was the main product. It is noteworthy that in both reactions the compounds 2 were obtained a single diastereoisomers.<smiles>OC(c1ccccc1)c1ccco1</smiles>

1

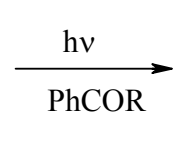

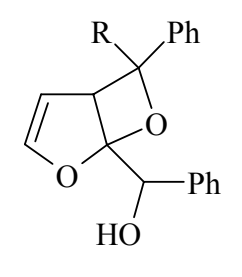

2

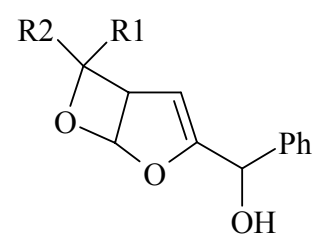

3

\section{Scheme 2}

In this work we used as substrate (5-methyl-2-furyl)benzylic alcohol (4) obtained from 5-methylfuran-2-carbaldehyde and phenyl magnesium bromide.<smiles>Cc1ccc(C(O)c2ccccc2)o1</smiles>

4

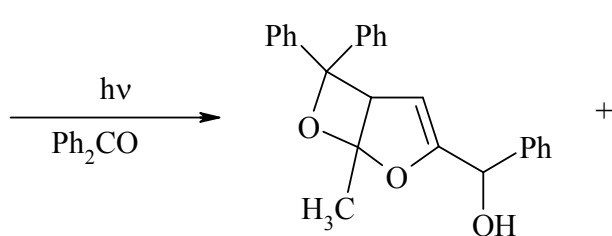

5<smiles>CC1=CC2C(c3ccccc3)(c3ccccc3)OC2(C(O)c2ccccc2)O1</smiles>

6

\section{Scheme 3}

The irradiation of 4 in the presence of benzophenone gave a 1:1 mixture of diastereomers 5 and 6 (Scheme 3) in 30\% and 33\% yield, respectively. The adduct 6 was a single diastereoisomer while 5 was a mixture of diastereoisomers.

The irradiation of 4 in the presence of benzaldehyde behaved differently: in this case we obtained $55 \%$ of 7 as a mixture of diastereoisomers, derived from the attack of benzaldehyde on the side of furan bearing the methyl group (Scheme 4). We have to notice that chemical shift of the proton at C-6 in the ${ }^{1} \mathrm{H}$ NMR spectrum points to formation of the exo isomer. 
The irradiation of 4 in the presence of 4,4'-dichlorobenzophenone gave a mixture of two products (Scheme 5): compound 8 was obtained in $30 \%$ yield as a single diastereoisomer, derived from the attack on the side of furan bearing the alcohol and 9 in 12\% yield derived from the attack on the side of furan bearing the methyl group. The latter product was separated as a 1:1 mixture of diastereoisomers.<smiles>Cc1ccc(C(O)c2ccccc2)o1</smiles>

4

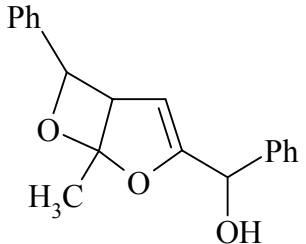

7

\section{Scheme 4}<smiles>Cc1ccc(C(O)c2ccccc2)o1</smiles>

4

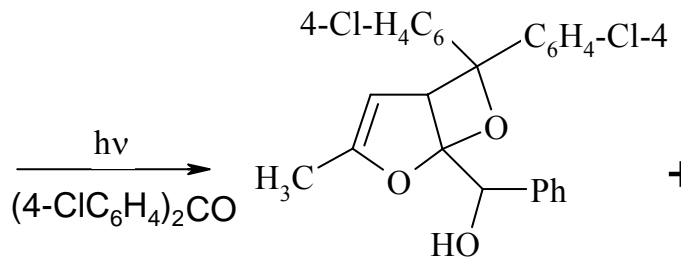

8

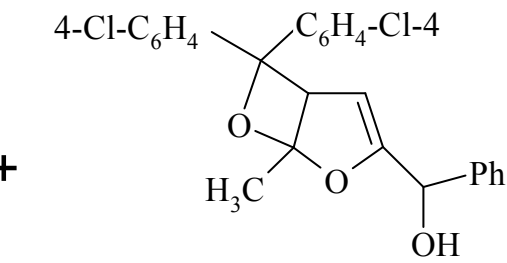

9

\section{Scheme 5}

When the reaction was carried out in the presence of 4,4'-dimethoxybenzophenone, we obtained only 10 in 58\% yield as a 1:1 mixture of diastereoisomers (Scheme 6). A similar result (11 in $60 \%$ yield) was obtained using 4-methoxybenzaldehyde as a carbonyl reagent (Scheme 7): 4methoxybenzaldehyde attacks 4 on the side of furan bearing the methyl group. Furthermore, ${ }^{1} \mathrm{H}$ NMR data agree with the formation of an endo isomer as a 1:1 mixture of diastereoisomers.<smiles>CCCCCCCC(=O)OCCCCCC(=O)OC(O)c1ccc(C)o1</smiles>

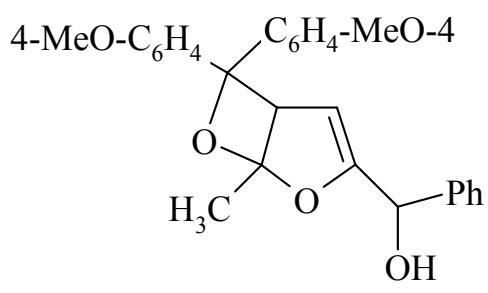

10

\section{Scheme 6}




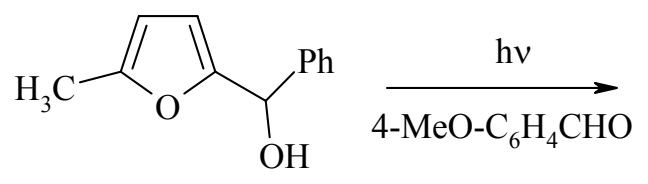

4

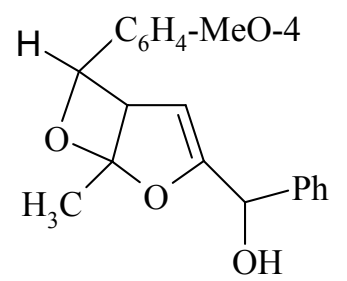

11

\section{Scheme 7}

In conclusion, we observed that the presence of a methyl group in C-5 on the furan ring induces a modification in the regioselectivity and dramatic loss in stereoselectivity of the reaction.

For 2-furylmethanol derivatives we observed a good regioselectivity towards the side of the furan bearing the alcohol. ${ }^{14}$ In this work we found that this regioselectivity is maintained when $4,4^{\prime}$-dichlorobenzophenone is used as a carbonyl reagent. When the reaction was carried out in the presence of benzophenone, we obtained a 1:1 mixture of regioisomers and, when 4methoxybenzaldehyde or 4,4'-dimethoxybenzophenone were used, we again observed a good regioselectivity again although on the other side of the furan ring. Furthermore, for 2furylmethanol derivatives the reaction showed a high stereoselectivity: in most of the reactions one diastereoisomer was formed. In this work, a similar result was obtained only using 4,4'dichlorobenzophenone: in all the other cases mixtures of diastereoisomers were obtained. Furthermore, among the products obtained using benzophenone, one (6) is a single diastereoisomer, while the other (5) consists of a mixture of diastereoisomers.

Thus, a clear change in the regioselectivity going from 4,4'-dichlorobenzophenone (attack on positions 2,3) to 4,4'-dimethoxybenzophenone (attack on positions 4,5) can be seen, benzophenone showing an intermediate behavior. In our previous work ${ }^{14}$ we formulated the hypothesis that the photochemical reaction of 2-furylmethanols with aromatic ketones involves a single electron transfer from the furan derivatives to the ketone followed by radical coupling with the formation of zwitterionic species. In contrast with current opinions in this field, ${ }^{1}$ we thought that the most probable structures for these zwitteronic species would be those represented in the Figure. Our point of view can be supported by results of theoretical calculations showing that stability of intermediates explains the regiochemical behavior of the reaction. ${ }^{14}$

We tested this hypothesis trying to explain the observed regiochemical behavior on 4 by respective calculatons. The results are collected in the Table. Total electronic energies for selected intermediates calculated using PM3 semiempirical method (HyperChem) correlate with the experimental results. For 4,4'-dichlorobenzophenone, the attack on the positions 2,3 is more possible while in the case of $4.4^{\prime}$-dimethoxxybenzophenone, the attack on the positions 4,5 is favored. Furthermore, in the case of benzophenone, the energies of the possible intermediates are similar. 

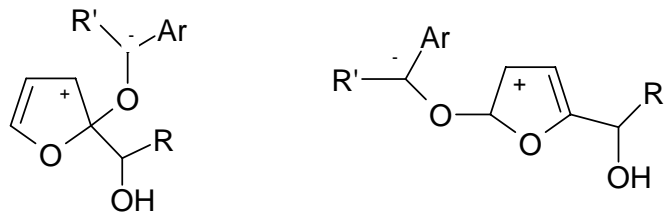

Figure 1. Most probable intermediates in the reaction of 2-furylmethanols with aromatic carbonyl compounds.

The stereochemical behavior of the reaction has to be discussed too. While 6 and 8 are produced as single diastereosomers, 5, 7, 9, 10, and 11 are diastereoisomeric mixtures. In our previous work compounds 2 were obtained as single diastereoisomers. ${ }^{14}$ In order to explain this stereochemical behavior we considered the possibility that the hydroxy group favors an approach of the carbonyl group towards a prochiral face of the furan. Our results confirm this assumption. In fact, when the reaction occurs on the side of furan bearing the hydroxy group at the side chain and an interaction between the hydroxy group and the carbonyl reagent is possible, we obtain a high stereoselectivity. On the contrary, when the reaction occurs on the side of furan bearing the methyl group so the interaction between the hydroxy group and the carbonyl reagent can not be important, the reaction shows no stereoselectivity.

In conclusion, we have shown that the photochemical cycloaddition of 5-methyl-2furylmethanol derivatives with aromatic carbonyl compounds leads to the formation of the corresponding Paterno-Büchi adducts. In most cases the reaction occurs with the preferential formation of regioisomers deriving from the attack on the side of furan bearing the methyl group. The regio- and stereoselectivity can be explained on the basis of the mechanistic hypotheses formulated in our previous work in this field. 
Table 1. Total electronic energy for selected intermediates in the reaction of 4 with benzophenone derivatives

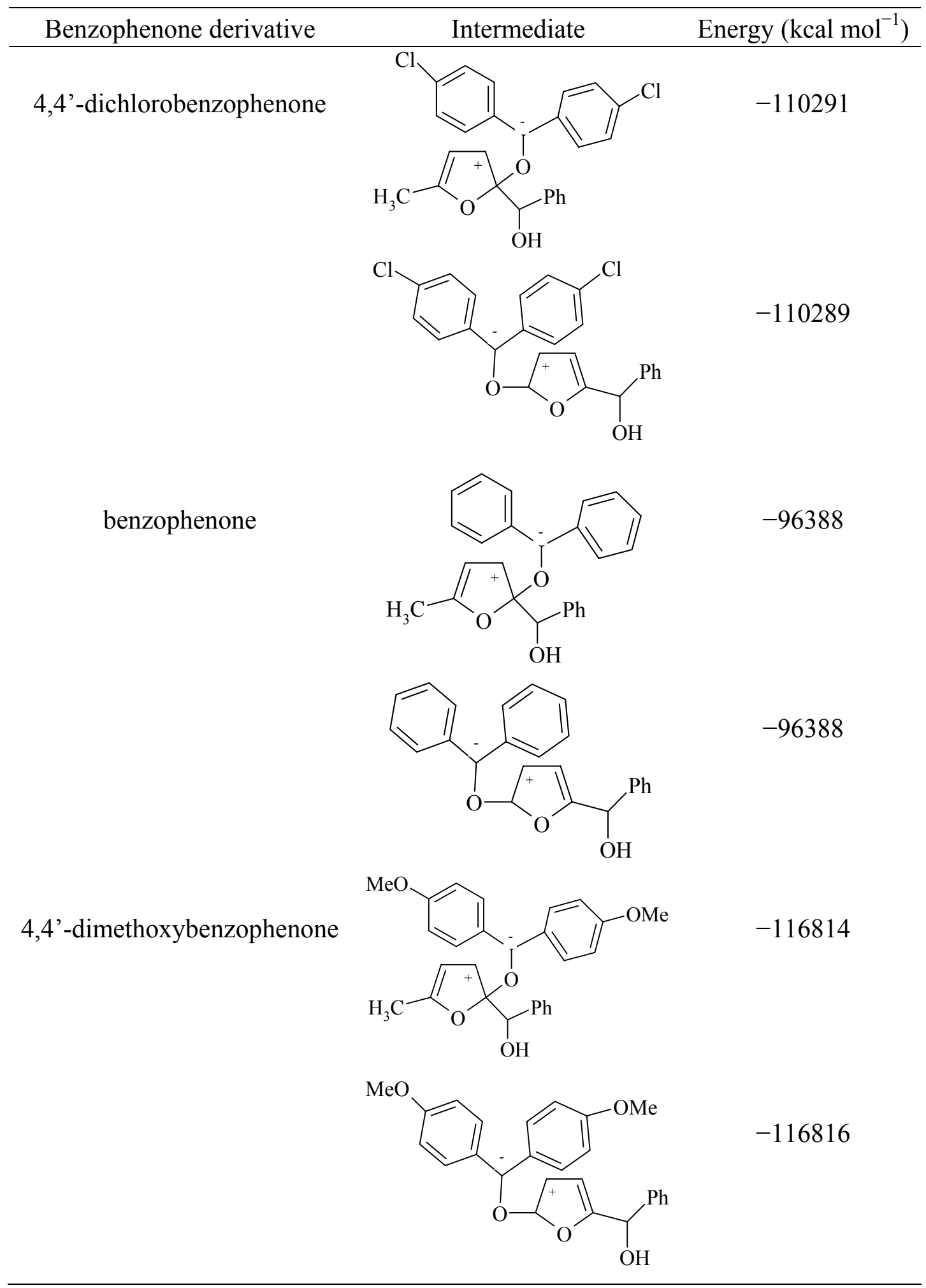




\section{Experimental Section}

General Procedures. NMR spectra were recorded on a Bruker 300 AM instrument. 2Furylmethanol derivatives were prepared through the reaction of suitable Grignard reagents with 5-methyl-furan-2-carbaldehyde (Aldrich).

Caution! While performing NMR spectra of cycloadducts we noticed that deuterated chloroform purchased from Aldrich induced a retro-cycloaddition reaction giving, within an hour, the starting materials. We did not observe this behavior using deuterated chloroform from Fluka or Carlo Erba. We inquired Aldrich about the presence of metals or some other trace impurities in deuterated chloroform, able to give this type of reaction. Until now, we did not receive any reply from Aldrich. Therefore we think we should aware our readers on this possible trouble.

General procedure for cycloaddition reaction between 2-furylmethanols and carbonyl compounds

2-Furylmethanol derivative $4(10 \mathrm{mmol})$ was dissolved in benzene $(70 \mathrm{~mL})$ in the presence of the carbonyl compound $(15 \mathrm{mmol})$. The mixture was flushed with nitrogen for $1 \mathrm{~h}$ and, then, irradiated with a $125 \mathrm{~W}$ high-pressure mercury arc (Helios-Italquartz). At the end of the reaction, the removal of the solvent yielded a crude product that was chromatographed on silica gel. The elution with $n$-hexane/ethyl acetate mixtures gave pure products.

1-Methyl-3-(phenylmethyl-1-ol)-6,6-diphenyl-2.7-dioxabicyclo[3.2.0]hept-3-ene (5). ${ }^{1} \mathrm{H}$ NMR $\left(\mathrm{CDCl}_{3}, 300 \mathrm{MHz}\right) \delta: 7.5-6.9(\mathrm{~m}, 15 \mathrm{H}$, aromatic protons), 4.69 (d, $1 \mathrm{H}, J=4 \mathrm{~Hz}, \mathrm{C} 4-\mathrm{H}), 4.43$ $(\mathrm{m}, 2 \mathrm{H}, J=4 \mathrm{~Hz}, \mathrm{C} 5-\mathrm{H}$ and $\mathrm{CHOH}), 1.90(\mathrm{~s}, 1 \mathrm{H}, \mathrm{OH}), 1.65\left(\mathrm{~s}, 3 \mathrm{H}, \mathrm{CH}_{3}\right) .{ }^{13} \mathrm{C} \mathrm{NMR}\left(\mathrm{CDCl}_{3}\right)$

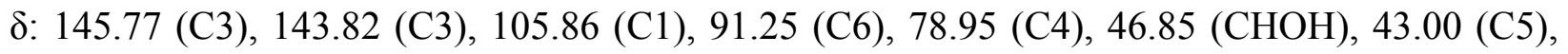
$29.60\left(\mathrm{CH}_{3}\right), 27.60\left(\mathrm{CH}_{3}\right)$.

1及-(Phenylmethyl-1-ol)-3-methyl-6,6-diphenyl-2,7-dioxabicyclo[3.2.0]hept-3-ene (6). ${ }^{1} \mathrm{H}$ NMR $\left(\mathrm{CDCl}_{3}, 300 \mathrm{MHz}\right) \delta: 7.6-7.0(\mathrm{~m}, 15 \mathrm{H}$, aromatic protons $), 5.19(\mathrm{~m}, 1 \mathrm{H}, \mathrm{CHOH}), 4.69(\mathrm{~m}, 1 \mathrm{H}$, $\mathrm{C} 4-\mathrm{H}), 4.18(\mathrm{~m}, 1, \mathrm{C} 5-\mathrm{H}), 2.03(\mathrm{~s}, 1 \mathrm{H}, \mathrm{OH}), 1.57\left(\mathrm{~s}, 3 \mathrm{H}, \mathrm{CH}_{3}\right) .{ }^{13} \mathrm{C} \mathrm{NMR}\left(\mathrm{CDCl}_{3}\right) \delta: 145.0$ (C3), 107.8 (C1), 106.2 (C4), $92.3(\mathrm{C} 6), 60.3(\mathrm{CHOH}), 57.8(\mathrm{C} 5), 17.50\left(\mathrm{CH}_{3}\right)$.

1-Methyl-3-(phenylmethyl-1-ol)-6ß-phenyl-2,7-dioxabicyclo[3.2.0]hept-3-ene (7). ${ }^{1} \mathrm{H}$ NMR $\left(\mathrm{CDCl}_{3}, 300 \mathrm{MHz}\right) \delta: 7.7-7.2(\mathrm{~m}, 10 \mathrm{H}$, aromatic protons $), 5.55(\mathrm{~m}, 1 \mathrm{H}, \mathrm{C} 4-\mathrm{H}), 5.37(\mathrm{~m}, 1 \mathrm{H}$, $\mathrm{CHOH}), 5.17$ (m, $1 \mathrm{H}, \mathrm{C} 6-\mathrm{H}), 3.55$ (m, $1 \mathrm{H}, \mathrm{C} 5-\mathrm{H}), 2.27$ (s, $1 \mathrm{H}, \mathrm{OH}), 1.25\left(\mathrm{~s}, 1.5 \mathrm{H}, \mathrm{CH}_{3}\right), 1.20$ $\left(\mathrm{s}, 1.5 \mathrm{H}, \mathrm{CH}_{3}\right) .{ }^{13} \mathrm{C} \mathrm{NMR}\left(\mathrm{CDCl}_{3}\right) \delta: 141.3$ (C3), $110.6(\mathrm{C} 1), 108.6(\mathrm{C} 4), 91.7$ (C6), 66.2 $(\mathrm{CHOH}), 50.3(\mathrm{C} 5), 32.1\left(\mathrm{CH}_{3}\right) 30.4\left(\mathrm{CH}_{3}\right)$.

1及-(Phenylmethyl-1-ol)-3-methyl-6,6-di-(4-chlorophenyl)-2,7-dioxabicyclo[3.2.0]-hept-3-ene (8). ${ }^{1} \mathrm{H} \mathrm{NMR}\left(\mathrm{CDCl}_{3}, 300 \mathrm{MHz}\right) \delta: 7.4-7.1$ (m, $13 \mathrm{H}$, aromatic protons), $4.78\left(\mathrm{~d}, 1 \mathrm{H}, J_{1}=3\right.$ Hz, C4-H), 4.38 (m, 1 H, CHOH), 4.29 (d, 1 H, J = 3 Hz, C5-H), 2.4 (br s, $1 \mathrm{H}, \mathrm{OH}), 1.69$ (s, 3

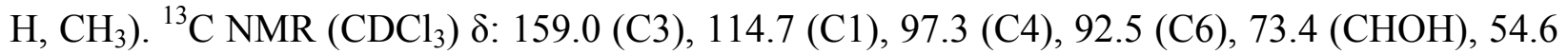
(C5), $30.8\left(\mathrm{CH}_{3}\right)$.

1-Methyl-3-(phenylmethyl-1-ol)-6,6-di-(4-chlorophenyl)-2,7-dioxabicyclo[3.2.0]-hept-3-ene (9). ${ }^{1} \mathrm{H} \mathrm{NMR}\left(\mathrm{CDCl}_{3}, 300 \mathrm{MHz}\right) \delta: 7.5-7.1$ (m, $13 \mathrm{H}$, aromatic protons), 5.95 (d, $1 \mathrm{H}, \mathrm{J}=3 \mathrm{~Hz}$, 
C4-H), 5.90 (s, $1 \mathrm{H}, \mathrm{CHOH}), 5.78$ (m, $1 \mathrm{H}, \mathrm{C} 5-\mathrm{H}), 2.5$ (br s, $1 \mathrm{H}, \mathrm{OH}), 1.78$ (s, $\left.1.5 \mathrm{H}, \mathrm{CH}_{3}\right), 1.70$ (s, $\left.1.5 \mathrm{H}, \mathrm{CH}_{3}\right) .{ }^{13} \mathrm{C} \mathrm{NMR}\left(\mathrm{CDCl}_{3}\right) \delta: 154.2(\mathrm{C} 3), 152.3$ (C3), 108.4 (C1), 106.1 (C1), 97.4 (C4), 92.5 (C6), $70.2(\mathrm{CHOH}), 54.5(\mathrm{C} 5), 13.5\left(\mathrm{CH}_{3}\right)$.

1-Methyl-3-(phenylmethyl-1-ol)-6,6-di-(4-methoxyphenyl)-2,7-dioxabicyclo-[3.2.0]hept-3ene (10) $.{ }^{1} \mathrm{H} \mathrm{NMR}\left(\mathrm{CDCl}_{3}, 300 \mathrm{MHz}\right) \delta: 7.8-6.5(\mathrm{~m}, 13 \mathrm{H}$, aromatic protons), $3.85(\mathrm{~s}, 1.5 \mathrm{H})$, $3.75(\mathrm{~m}, 3 \mathrm{H}), 3.70(\mathrm{~s}, 1.5 \mathrm{H}), 3.64(\mathrm{~s}, 1.5 \mathrm{H}), 3.52(\mathrm{~s}, 1.5 \mathrm{H}), 2.23(\mathrm{~s}, 1 \mathrm{H}), 1.17(\mathrm{~s}, 1.5 \mathrm{H}), 1.12$ (s, $1.5 \mathrm{H}) .{ }^{13} \mathrm{C} \mathrm{NMR}\left(\mathrm{CDCl}_{3}\right) \delta: 160.7(\mathrm{C} 3), 113.8(\mathrm{C} 1), 113.5(\mathrm{C} 4), 85.2(\mathrm{C} 6), 82.8(\mathrm{CHOH})$, $55.3(\mathrm{C} 5), 23.8\left(\mathrm{CH}_{3}\right), 20.8\left(\mathrm{CH}_{3}\right), 17.5\left(\mathrm{CH}_{3}\right), 17.3\left(\mathrm{CH}_{3}\right), 14.6\left(\mathrm{CH}_{3}\right)$.

1-Methyl-3-(phenylmethyl-1-ol)-6ß-(4-methoxyphenyl)-2,7-dioxabicyclo[3.2.0]-hept-3-ene (11). ${ }^{1} \mathrm{H}$ NMR $\left(\mathrm{CDCl}_{3}, 300 \mathrm{MHz}\right) \delta: 7.5-6.5\left(\mathrm{~m}, 9 \mathrm{H}\right.$, aromatic protons), $5.22\left(\mathrm{~d}, 1 \mathrm{H}, J_{1}=4\right.$ Hz, , C6-H), 3.90 (s, 1.5 H), 3.79 (m, 4.5 H), 3.74 (s, 1.5 H), 3.68 (s, 1.5 H), 2.33 (s, 1 H, OH), $1.21(\mathrm{~s}, 1.5 \mathrm{H}), 1.14(\mathrm{~s}, 1.5 \mathrm{H}) .{ }^{13} \mathrm{C}$ NMR $\left(\mathrm{CDCl}_{3}\right)$ 8: 137.7 (C3), 114.2 (C1), 113.9 (C4), 80.4 (C6), $65.5(\mathrm{CHOH}), 55.3(\mathrm{C} 5), 23.8\left(\mathrm{CH}_{3}\right), 20.8\left(\mathrm{CH}_{3}\right), 17.5\left(\mathrm{CH}_{3}\right)$.

\section{References}

1. Griesbeck, A. G.; Buhr, S.; Fiege, M.; Schmickler, H.; Lex, J. J. Org. Chem. 1998, 63, 3847.

2. Griesbeck, A. G. In Handbook of Organic Photochemistry and Photobiology Horspool, W. M.; Song, P. J. Eds, CRC Press: Boca Raton, 1995, p 550.

3. Porco, J. A.; Schreiber, S. L. In Comprehensive Organic Synthesis (Ed. by B. M. Trost and L. A. Paquette), Plenum Press, New York, 1991, 5, 151.

4. Carless, H. A. J. In Synthetic Organic Photochemistry Horspool, W. M. Ed., Plenum Press: New York, 1984, p 425.

5. Jones, G. Organic Photochemistry, 1981, 5, 1.

6. Schreiber, S. L. Science, 1985, 227, 857.

7. Schreiber, S. L.; Hoveyda, A. H.; Wu, H. -J. J. Am. Chem. Soc., 1983, 105, 660.

8. Schreiber, S. L.; Satake, K. J. Am. Chem. Soc., 1984, 106, 4186.

9. Schreiber, S. L.; Hoveyda, A. H. J. Am. Chem. Soc., 1984, 106, 7200.

10. Schreiber, S. L.; Desmaele, D.; Porco, J. A. Tetrahedron Lett., 1988, 29, 6689.

11. Schreiber, S. L.; Porco, J. A. J. Org. Chem., 1989, 54, 4721.

12. Just, G. In Photochemical Key Steps in Organic Synthesis Mattay, J.; Greisbeck A. Eds, VCH: Weinheim, 1994, p 42.

13. Carless, H. A. J.; Halfhide, F. E. J. Chem. Soc., Perkin Trans. 1, 1992, 1081.

14. D'Auria, M.; Racioppi, R.; Romaniello, G. Eur. J. Org. Chem., submitted. 